COMMENT

https://doi.org/10.1057/s41599-019-0370-2

\title{
OPEN
}

\section{The IGAD Kampala Declaration on jobs, livelihoods, and self-reliance: from declaration to reality}

Gail Hopkins $^{1 \star} \&$ Laura Buffoni ${ }^{2}$

\section{ABSTRACT}

The Kampala Declaration on Jobs, Livelihoods, and Self-Reliance for Refugees, Returnees, and Host Communities, signed in March 2019 by IGAD member states, contains commitments which are an important part of realizing the objectives of the Global Compact for Refugees in the IGAD region. The Declaration holds real potential for realizing Compact objectives globally and builds on the 2017 Nairobi Declaration on Durable Solutions for Somali Refugees. Over past years, dramatic changes to contemporary global policy relating to refugees situates refugees within receiving communities and receiving states and promotes a 'whole of society' approach. The Kampala Declaration forms part of this change and, as such, the realization of Declaration commitments is crucial. With the upcoming Global Refugee Forum in December 2019 providing an opportunity to take stock of progress, the article emphasizes the crucial importance of planned and active participation, inclusion and collaboration of all parties as being fundamental in realizing in practice refugees' right to work and access to economic opportunities. Attention is drawn to 'missed opportunities' within elements of the Kampala meeting and premeeting process which resulted in the impairment of potential for success and effective dialog. Further attention is drawn to critical areas where mindfulness in future meetings/dialog can be beneficial in order to effectively catalyze future change. Because the Kampala Declaration commitments form a central role in realizing Global Compact objectives, the article argues for high level meetings and fora to prioritize an approach to discussions which creates enabling contexts of formal but inclusive dialog. The article calls for better planning in this respect and puts forward suggestions for how dialog might become more productive. The article sets the context and aims of the Kampala meeting, moving forward to highlight areas needed to effectively catalyze change and then looks at meeting planning and participation,. Some brief examples are presented, continuing on to suggest ways in which changes in approach can transform reality. The article concludes, importantly, that the Kampala Declaration demonstrates that the commitment and language of inclusion exist. What remains is for truly collective action to ensure the Declaration achieves its transformative potential.

\footnotetext{
${ }^{1}$ University of Sussex, School of Global Studies, Brighton, UK. ${ }^{2}$ UNHCR, Nairobi, Kenya. *email: ghopkns@gmail.com
} 


\section{Kampala Declaration-setting the context}

osted by the Government of the Republic of Uganda, on 28th March 2019 the Inter-Governmental Authority on Development (IGAD) convened a regional ministerial meeting which resulted in the signing of the Kampala Declaration on Jobs, Livelihoods, and Self-Reliance for Refugees, Returnees, and Host Communities ${ }^{1}$. Member state participants also developed an Action Plan to operationalize the agreed commitments of the Declaration. The meeting was supported by a core group: EU, UNHCR, UNHCR, ILO, WB, and REDSS comprising experts, and policymakers.

The Kampala meeting grew out of the 2017 Nairobi Declaration on Durable Solutions for Somali Refugees. The Nairobi process was initially designed to address the lack of solutions available to the displacement of Somalis, but transformed into a discussion on solutions for all refugees in the region with followup annual stocktaking meetings providing opportunities to discuss progress (IGAD, 2019). The Kampala Declaration meeting picked up some identified transformative points of Nairobi-such as national systems, partnerships, alternatives to refugee camps, free movement, refugee work rights, self-reliance, economic inclusion, and the 'whole of society' approach-and translated them into a Declaration and Plan with a framework for the wider IGAD region.

This article focuses on the task of transforming into reality the inspirational commitments made at Kampala, and centers the value of planned and active participation, inclusion and collaboration of all parties as fundamental in realizing in practice the right to work and access to economic opportunities. This is especially pertinent in relation to realizing the objectives of the Global Compact for Refugees (GCR). The article comments on parts of the process leading up to the Kampala meeting and the meeting itself, and suggests constructive ways in which to maximize the commitments within the Kampala Declaration both now and in future meetings/dialogs/actions of IGAD, member states and other stakeholders. This discussion is particularly timely in view of the upcoming first Global Refugee Forum ${ }^{2}$ to be held in December 2019, one of the main follow-up provisions within the Compact.

Over the past few years there have been dramatic changes to the contemporary global policy toward refugees, for example the 2016 New York Declaration, the Comprehensive Refugee Response Forum (CRRF) rolled out in 2017/18, and the 2018 Global Compact on Refugees. In addition, there have been changes in the way UNHCR approaches solutions for displaced populations with a clear emphasis on the right to work, on dignity and self-reliance and on host community economies. These changes situate refugees within receiving communities and receiving states and, consequently, require national development agendas and national legal frameworks to adapt to ensure refugee inclusion and a 'whole of society' approach. The Kampala Declaration forms part of this adaptation.

The need for refugees' economic inclusion in planning and national development agendas and legal frameworks is widely discussed: for example, Ayoubi and Saavedra (2018) identify legal frameworks to enable the economic inclusion of refugees whilst also generating benefits for host countries if accompanied by consistent and predictable development funding in individual host communities, while others have critiqued the current system and offered suggestions ${ }^{3}$ but without taking account of the influence states have over decisions and policymaking regarding humanitarian work.

Much work has been done toward achieving objectives, however The Center for Global Development (2018) reported that, '[e]xperience so far indicates that overall governance structures are fragmented; goals, policy changes, and program plans are not yet clear or fully aligned with resources and there are few mechanisms holding all actors to account for achieving results for refugees and their host.' More recently, a review by ODI (2019) of the CRRF in Ethiopia, Kenya, Rwanda and Uganda finds mixed outcomes and whilst there is some progress, 'high-income countries and donor governments are largely failing in their commitment to share responsibility for refugees.'

The Kampala Declaration is a concrete expression of the contemporary direction of refugee management and of increasingly progressive policymaking to address gaps and programmatic shortfalls and poor outcomes. Two points addressed in the Declaration-moving beyond refugee camps and allowing refugees access to work-create the potential to be truly transformative in the IGAD region and to make the region a model for the rest of the world.

However, a number of provisos remain for the narrative to effectively catalyze change:

1. The Declaration is a non-binding document that can only become a reality if underpinned by legislation.

2. There is a need for robust support through predictable investments that create local economic opportunities and presuppose a new relation between refugees and development agendas.

3. Informal and invisible barriers to refugees' economic inclusion, including ignorance of refugees' right to work, by the public, employers and authorities to be tackled.

4. Increased attention needed on refugee and host realities on the ground to avoid isolating process from lived experience: formalize refugees' input to knowledge and policymaking.

With the potential for transformation in mind, it is critical that high level meetings, such as Kampala, which formulate decisions and commitments, create enabling contexts of formal but inclusive dialog with planned potential to adjust existing legal and administrative frameworks upon which policy, practice and operations hang. This is particularly important for IGAD countries which, though having severe economic challenges, host large refugee numbers in their most marginalized and underdeveloped areas. For example, Maban county in South Sudan hosts 144,000 refugees among 45,238 local population; Gambella region of Ethiopia hosts 401,594 refugees among 435,999 local population ${ }^{4}$, and the population of Turkana West in Kenya has approximately 186,000 refugees and 320,000 host.

A look at the preparation for the Kampala meeting, and the meeting itself, highlights where potential was impaired at meeting and pre-meeting stages, and therefore where opportunities for future meetings/dialogs exist through which to enhance progress in action.

\section{Pre-meeting information and research; 'whole of society' approach}

In preparation for the meeting, a consultant drew on large amounts of information to prepare a concept note, a comprehensive background paper and a shorter note to include specific questions for the five working sessions of the meeting.

This information formed the basis of discussion during the Kampala meeting. In retrospect, a more productive approach could have been to constitute a pre-meeting drafting committee to include IGAD and member state line ministry staff (Labor and Social Affairs, Economic Planning, Agriculture) supported by the core group to hold country-level discussions as a preparatory stage.

Preliminary discussions would allow time for consultation, learning and, critically, buy-in by those who will design and promote the administrative measures necessary for refugees to 
access work, land and business permits. Specifically involving line ministries in charge of labor, business licensing, and land allocation at decentralized levels in a preliminary stage would facilitate sketching out administrative measures, countering resistance within line ministries and easing the way to a workable outcome. Overall, this approach would reflect the 'whole of society' vision promoted through the GCR. As it was, there was a short amount of time between receiving the briefing documents and the meetings, resulting in practitioners and ministries attending Kampala perhaps not having sufficiently absorbed decisions and information and consequently lacking the time to effectively brief their respective administrations and proactively promote change. Preliminary discussions would importantly allow the in-country expertize of IGAD member States' to be utilized. An opportunity for collaborative learning, inclusively designing regulatory and administrative changes, and creating functional enabling environments was missed at Kampala but could be accommodated in future.

\section{Meeting session focussing on policy and legislative opportunities/constraints}

This particular session of the Kampala meeting highlighted the lack of job opportunities in deeply underdeveloped environments hosting refugees and the realization that only development can address the lack of options for livelihoods and economic selfreliance. However, it was inspiring that most countries felt refugees should be permitted access to work, land and business permits and that systematic use of labor market assessment and impact indicators were deemed essential.

Djibouti, Ethiopia, and South Sudan presented positive attitudes toward refugees' economic inclusion, strongly promoting the most generous options for refugees to access work, land and financial inclusion. Uganda described their positive enabling environment, despite the absence of updated refugee law, but warned against policies and programming that would tilt the balance in favor of refugees. Uganda's caution underlines the importance of planning for economic inclusion in collaboration with the whole of society, including in-country expertize. In largely informal economies such as Sudan where over two million refugees in 24 camps seek work in an organized but informal context, future practical challenges were highlighted regarding efforts to avoid tilting the balance whilst also supporting refugees' economic inclusion via issuing work permits. South Sudan contributed a solution: refugee access to land surrounding camps and a liberal approach to movement.

\section{Refugee participation in the meeting sessions}

Refugee participation at Kampala was limited. The meeting would have been more productive with more refugee participants, enabling interactive first-hand dialog around needs, constraints, challenges, successes and ideas drawn from refugee realities. Arranged by UNHCR Uganda, one refugee leader of South Sudanese origin living in Uganda opened the first afternoon's panel discussion and spoke charismatically. Her presence throughout the three days of debate was important but her wider involvement would have been useful either in the opening sessions or in technical sessions: understanding how policy and programming works out on the ground is key for practitioners and policymakers.

Sadly, the lengthy visa process prevented a group of Somali returnees from attending the meeting to share their experiences and, specifically, the meeting missed a scheduled opportunity to hear from them about their reintegration in Somalia, due to occur as part of a group exercise on 'making return and reintegration work'. The visa delay was an ironic reminder of the importance for IGAD member States to realize free movement protocols to benefit citizens and refugees alike.

Going forward, ensuring refugees' significant contribution, not only attendance, requires ongoing improvement by UNHCR at all important policy processes related to the GCR and at preparatory meetings leading up to the 2019 Global Refugee Forum. While speaking the language of inclusion, there is the need to also act out inclusion, recalling that refugees' input, or lack of input, to policymaking can directly impact their lives and futures. The 29.4 million refugees worldwide and the 4.13 million hosted by IGAD countries, as well as the many others who are displaced internally, deserve a say.

Concerning bringing lived experience to the process, some gaps to address are:

- While refugee groups and civil society organizations active in refugee protection have been engaged in the Global Compact for Refugees and related processes, a tendency exists to reiterate positions and be out of touch with the daily challenges of refugee life.

- The voice of refugee youth-the majority of refugees-is underrepresented. Their potential to debate eloquently refugee rights and viewpoints is being missed by the process. - The contribution of refugees in higher education and of businessmen and women could play a key role in providing unfiltered, genuine ideas and feedback.

As the High Commissioner for Refugees expressed recently it is important that we are able to go beyond the numbers, and help convey the brutal consequences of conflict, persecution and displacement, and the remarkable resilience of the people that find their way through these experiences, and rebuild their lives against the odds.... Creating space for the voices of refugees to be heard, are key aspects of UNHCR's work'.

Kampala follow-up: challenges for IGAD and the core group Ethiopia's recent Refugee Proclamation (National Legislative Bodies, 2019) is an example of the challenge ahead. Although one of the most progressive in the IGAD region the Proclamation is nonetheless more restrictive than the Kampala Declaration. Kenya provides a further example, needing to make significant progress especially on freedom of movement to align with some of the Kampala Declaration's commitments. Furthermore, regulations upon which realization of the rights determined under the Declaration are contingent, remain weak or non-existent in several IGAD countries, in particular, where access to decent work and rights at work might not meet international standards for all workers in the country.

IGAD itself has some very competent staff with the ability to mobilize states around specific themes. This is key to progress, combined with UNHCR's commitment to supporting IGAD through platforms and committees, existing and new, with the collective aim of realizing the changes needed in national legislation and administrative arrangements to create a real pathway to refugee economic activity and access to livelihood opportunities, to which refugees already have the legal right.

Because the overarching responsibility and energy has to be invested by IGAD member countries, only their collective responsibility to create jobs and opportunities for all-refugees, returnees and member state nationals-and their success at mobilizing international support based on progressive policies and supported by adequate governance will bring change. Improved legal frameworks, whilst undeniably beneficial, are not sufficient: concerted, effective work directly tied to impact is required, including addressing those invisible barriers to refugees' economic inclusion. 


\section{Forging a way forward; creating reality}

Translating language into action is crucial in transforming into reality the promising text of the Kampala Declaration. Resolute and dedicated follow-up (and follow through) by IGAD member states and the core group through UNHCR country level advocacy is central in ensuring that the Declaration's aspirational wording is able to influence new legislation and administrative process at national level, especially as the Declaration itself is non-legally binding.

Since Kampala, UNHCR has monitored the progress made on the commitments within the Declaration, and an important IGAD stocktaking exercise took place on 16-18 September 2019 in Addis Ababa. Through these, it is clear there is much work in progress but little policy change for the time being. The monitoring and stocktaking exercise shows the main challenges are: the realization of legal provision and translating those provisions into administrative and regulatory instruments, distributing institutional responsibilities within involved line ministries, allocating financial resources to create mechanisms, and finally, through these elements, making refugee access to livelihoods a reality.

There are wide differences between IGAD member states and between processes started by each country. It is hoped that the IGAD stocktaking exercise in addition to a Danish-funded Government to Government sharing event ${ }^{5}$ on CRRF experiences at the end of October 2019, plus discussions to be held at the Global Refugee Forum in December 2019 will ensure the exchange of practices much supported by IGAD.

Collective and collaborative actions are key in order to substantially move forward on the jobs and livelihoods agenda for refugees and other persons affected by displacement. Of particular importance is the essential collaboration of UNHCR and the ILO at national level. ILO has the important advantage of a privileged constituency base with employers, ministries of labor and trade unions, in addition to having the mandate (ILO, 2016), and has experience in promoting refugee labor rights, especially following their implementation of the Compacts on Syrian refugees in the Middle East. An example of positive collaborative action is the implementation of the innovative multi-agency, multi-country initiative promoted by The Netherlands in support of jobs and education for refugees and host communities: an important step in the direction of collective action ${ }^{6}$.

Predictable and ring-fenced investments and the attraction of development resources are required in individual refugee hosting locations in order for countries to confidently move into an inclusion space and are required to underpin responsibilitysharing and a support platform-both of which are planned arrangements under the Global Compact for Refugees and the Global Refugee Forum-and a collective political process.

\section{Conclusion}

The Kampala Declaration on jobs, livelihoods and self-reliance for the IGAD region demonstrates that the commitment and language exist. What remains is for collective action to ensure outmoded models of response to displaced and vulnerable populations and host States are overwritten and re-designed. The way forward is clear: interactive, adaptive, multi-way support between UNHCR/receiving States/other agencies, the international community and refugees within a revitalized and inclusive legal, policy and practice framework reflecting recent shifts in international policy.

There are current discussions on creating 'platforms' that will function as 'friends of IGAD'. The intention of the platforms is to continue to support the endeavors of Governments in the region. Terms of Reference are being drawn up and represent a positive step toward realizing refugee access to work, free movement and financial services. Platform members will include a range of stakeholders: IGAD and non-IGAD members, donor Governments, private sector and civil society, as well as UNHCR and the wider UN community. Taking up a support or advisory role (being involved yet not involved), platform members would offer, as needed, expertize on process, policy, and legal aspects and would perform monitoring. The platforms would play an important role in the future success of the high-level political commitments of the Kampala Declaration by continuously monitoring through dialog with the public and with refugee communities.

However, if the platforms concept goes ahead there will be a need to embed in their functioning a method to ensure that incountry processes connect with line ministries, technical institutions, administrative and communication departments, law enforcement and the public, in order to bring about, in reality, access to work and services for refugees. Political commitments have advanced well in the region but concrete provisions and dissemination are needed in order to realize change for refugees and to create buy-in of stakeholders.

It is crucial that more opportunities are created for all, and that public information and communication within a refugee hosting country is strengthened to become inclusive of all. Unless this happens, limited and/or dysfunctional labor markets and widening inequalities will render it increasingly difficult to promote and transform into reality increased access to rights for refugees or real social cohesion and inclusion. The proposed platforms could become important spaces through which to facilitate and monitor transformation in a way that creates important 'buy-in' by all parties.

The forthcoming Global Refugee Forum in December 2019 is where the commitments of IGAD member states will be showcased and strengthened, thus reinforcing the Kampala Declaration as a model for other regions-and other regional bodies-in the world.

As ODI (2019) states, 'There is greater acceptance among hosting governments, donors and aid actors of more inclusive approaches to refugees'. Now, the inspirational commitments in the Declaration - if translated into legislation and administrative process-can be as transformative globally for refugees' right to work as the OAU Convention was for refugee management on the African continent.

However, failing to act collectively, inclusively and with vision and to move away from outmoded models of response will reduce the transformative potential of the Kampala Declaration's commitments and 'risks perpetuating the current system of isolating refugees in remote, impoverished regions where continued dependency on humanitarian assistance is a likely outcome' (ODI, 2019). Such a failure will impact negatively on refugees and host societies both in the IGAD region and the world.

Received: 18 September 2019; Accepted: 5 November 2019; Published online: 09 December 2019

\section{Notes}

1 Declarations and Recommendations cannot be ratified. The terms are often deliberately chosen to indicate that the parties do not intend to create binding obligations but merely want to declare certain aspirations. The Declaration can be seen at: https://www.unhcr.org/afr/publications/legal/5c9dd6384/kampala-declaration-onjobs-livelihoods-self-reliance-for-refugees-returnees.html

2 More about the GRF and how it connects to the GCR: www.unhcr.org/uk/globalrefugee-forum

3 E.g., Betts and Collier (2017); and Betts and Collier (2017).

4 UNHCR refugee figures; Maban County 2008 census (2017 projection 65,117); Ethiopian 2017 census. 
5 The Regional 'Government-to-Government' Conference: Delivering the Global Compact on Refugees: Local Approaches to Inclusion, 31st October to 1st November 2019 was intended to share experiences, identify forward-looking implementation opportunities for the Global Compact on Refugees and for the roll-out of the CRRF in the region.

6 For more information: https://www.ilo.org/pardev/donors/WCMS_648943/lang--en/ index.htm

\section{References}

Ayoubi Z, Saavedra R (2018) Refugee livelihoods: new actors, new models. Forced Migration Review 58:2018

Betts A, Collier P (2017) Refuge: transforming a broken refugee system. Allen Lane, London

Betts A, Collier P (2017) 'It doesn't have to be like this...'. The Independent, 27.03.2017. https://inews.co.uk/news/long-reads/ten-point-plan-fix-worldrefugee-system/. Accessed 18 Sep 2019

Centre for Global Development (2018) Tackling the realities of protracted displacement: case studies on what's working and where we can do better, April 2018. https://www.cgdev.org/sites/default/files/tackling-realities-protracteddisplacement-case-studies-whats-working.pdf

IGAD (2017) Nairobi Declaration on Durable Solutions for Somali Refugees and Reintegration of Returnees in Somalia, 25th March 2017. https://igad.int/ communique/1519-communique-special-summit-of-the-igad-assembly-ofheads-of-state-and-government-on-durable-solutions-for-somali-refugees

IGAD (2019) Communiqué of the Second Inter-Ministerial Stocktaking Meeting on the Nairobi Declaration and Action Plan. IGAD, 18 September 2019. Addis Ababa, Ethiopia. https://igad.int/press-release/2237-communique-ofthe-second-inter-ministerial-stocktaking-meeting-on-the-nairobideclaration-and-action-plan.

International Labour Organisation (2016) Guiding principles on the access of refugees and other forcibly displaced persons to the labour market. https:// www.ilo.org/wcmsp5/groups/public/---ed_protect/---protrav/---migrant/ documents/genericdocument/wcms_536440.pdf. Accessed 18 Sep 2019

National Legislative Bodies/National Authorities, Ethiopia: Proclamation No. 1110/ 2019, 27 February 2019. https://www.refworld.org/docid/44e04ed14.html. Accessed 18 Sep 2019
ODI (2019) The Comprehensive Refugee Response Framework: responsibilitysharing and self-reliance in East Africa, September 2019. https://www.odi.org/ publications/11451-comprehensive-refugee-response-frameworkresponsibility-sharing-and-self-reliance-east-africa

\section{Competing interests}

The authors declare no competing interests.

\section{Additional information}

Correspondence and requests for materials should be addressed to G.H.

Reprints and permission information is available at http://www.nature.com/reprints

Publisher's note Springer Nature remains neutral with regard to jurisdictional claims in published maps and institutional affiliations.

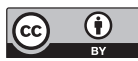

Open Access This article is licensed under a Creative Commons Attribution 4.0 International License, which permits use, sharing, adaptation, distribution and reproduction in any medium or format, as long as you give appropriate credit to the original author(s) and the source, provide a link to the Creative Commons license, and indicate if changes were made. The images or other third party material in this article are included in the article's Creative Commons license, unless indicated otherwise in a credit line to the material. If material is not included in the article's Creative Commons license and your intended use is not permitted by statutory regulation or exceeds the permitted use, you will need to obtain permission directly from the copyright holder. To view a copy of this license, visit http://creativecommons.org/ licenses/by/4.0/.

(C) The Author(s) 2019 